\title{
Assessment of Intervention Strategies for Addressing Agricultural Production Shocks in Tanzania: The Case of Rufiji, Mbarali and Sumbawanga Districts
}

\author{
Peter Samwel $^{1} \&$ Elliott P. Niboye ${ }^{2}$ \\ ${ }^{1}$ Dar es Salaam University College of Education, Tanzania \\ ${ }^{2}$ Institute of Development Studies, University of Dar es Salaam, Tanzania \\ Correspondence: Peter Samwel, Dar es Salaam University College of Education, P.O.Box 2329, Dar es Salaam, \\ Tanzania. E-mail: petersamwel@duce.ac.tz
}

Received: August 29, 2019

doi:10.5539/jsd.v12n6p1

\begin{abstract}
This study sought to gain in-depth understanding into smallholder farmers' perceptions of intervention strategies for addressing agricultural production shocks in Tanzania. It involved identification of local policy and intervention strategies that can be used to address agricultural production shocks and build resilience among smallholder farmers in Tanzania. The study employed mixed research methodology, using primary data collected from six villages in Sumbawanga, Mbarali and Rufiji districts in Tanzania. Overall findings reveal that smallholder farmers have good knowledge of possible strategies for addressing agricultural production shocks. The farmers recommended local policy and intervention strategies for supporting them such as facilitation of access to credit and subsidies, reinforcing and strengthening informal social networks, supporting income diversification activities and introduction of crop insurance system. Other intervention strategies include introduction of participatory village land use plans, promoting information access and training to smallholder farmers and enhancing access to small-scale irrigation technologies. Based on these findings, the study recommends that policy makers and researchers should concentrate on understanding farmers' perceptions in view of using local knowledge in the design and implementation of intervention strategies. The strength of farmers' perceptions is that it is the outcome of farmers' actual experience, and it is based on understanding of the local context. .The paper concludes that unless the strategies are fully implemented, agricultural production shocks will continue to affect smallholder farmers in rural Tanzania.
\end{abstract}

Keywords: smallholder farmers, local policy, resilience, vulnerability, coping strategies, rural livelihoods

\section{Introduction}

\subsection{Background to the Problem}

Africa is one of the regions in the world most affected by agricultural production variability. The continent's recurrent and long history of rainfall fluctuations of varying lengths and intensities along with inadequate infrastructure, limited storage facilities and market imperfections are among the major causes of agricultural production vulnerabilities. Agricultural production in sub-Saharan African countries is highly exposed to a wide range of natural disasters, with hydro-meteorological hazards affecting the largest number of people. Hydro-meteorological disasters in the region comprise cyclones, floods, landslides, wild fires and droughts. Droughts affect the largest number of people on the continent, followed by floods and storms (FAO, 2012).

At household level, production shocks have made livelihoods very difficult among rural communities of Africa. There has been a repeated succession of production shocks notably crop failures, mainly caused by drought and floods due to erratic rainfall patterns, often followed by very high prices, starvation and outbreak of diseases. Pests and disease lead to serious loss of crops in the field and in the storage. Losses of livestock, particularly cattle utilized for cultivation negatively affect crop production and food security of rural households (FAO, 2012).

Agriculture production in Africa operates under multiple idiosyncratic and covariant shocks. The shocks are related to variable prices caused by supply or demand, such as unfavourable policy interventions, and 
imperfections in input, output, credit and insurance markets. Also agriculture faces problems such as low prices for farmers' crops, inability of farmers to purchase and apply optimal fertilizers to the soils and inability of agro-pastoralists to access veterinary services for their livestock. Poor infrastructure in rural areas has led to development of thin output markets and consequently total market failure and high price volatility in rural areas (FAO, 2012).

Furthermore, rural households suffer from vulnerabilities associated with chronic illness, crime related attacks, disability and death. Over the last three decades, HIV/ AIDS has adversely affected agricultural production in rural Africa. Households affected by HIV/AIDS tend to divert their resources and time to caring of the sick at the expense of farm work (Zeller, 2000; FAO, 2012). Crime related attacks such as theft pose a major threat in agricultural activities. Loss of oxen due to theft adversely affects farm activities because households cannot cultivate their fields in a timely manner (Zeller, 2000; Zingore et al., 2008).

The importance of agriculture and its sensitivity to social, economic, climate and environmental shocks, has compelled farmers to adopt and implement various options in response to those shocks. The list of response options may be too long but the idea here is that depending on the context, stress, available resources both internal and external, farmers decide to choose from options they have, and try particular strategies so as to be able to cope and adapt to the specific risks and vulnerabilities (Ndaki, 2014). Below, et al., (2010), for example, mention improved farm management, technology use and farm financial management as some of the strategies employed by farmers in responding to climate shocks in Africa. Jain and Parshad (2007), mention crop diversification, plot diversification and mixed farming. Other commonly cited strategies include irrigation, multiple cropping and integration of livestock (Hassan and Nhemachena, 2008), changing planting dates, changing crop varieties as well as using various locally oriented and invented soil conservation techniques (Acquah \& Onumah, 2011).

In Tanzania, agriculture and vulnerability are closely linked due to the location of the rural households and their dependence on the agricultural sector. Data shows that about 75 per cent of Tanzanians live in rural areas and agriculture employs about 70 percent of total labour force (National Bureau of Statistics [NBS], 2014). Therefore, agricultural production vulnerabilities are likely to have profound impacts on the livelihoods of the majority of rural households.

Based on this background, the study sought to generate empirical data on possible strategies that can be used to address agricultural production shocks and build resilience to agricultural production shocks. In this study, attempt was made to capture smallholder farmers' experiences and perceptions in order to come up with strategies that are locally feasible and based on farmers' own experiences.

\subsection{Statement of the Problem}

Farming households in Tanzania have been experiencing a number of agricultural production shocks for decades (Dercon, 1996, 2000; Ahmed et al., 2011). These events include rainfall variability, droughts and floods that had at different points of time, affected rural livelihoods in the region (Mbiha et al.,, 2001; Shemsanga et al., 2010). For instance, droughts and rainfall variability have been responsible for food shortage in some areas of the Southern corridor between 2007 and 2010 (Mbilinyi, Saibul \& Kazi, 2013). Exposure to production vulnerabilities drives farming households to adopt various response options to mitigate adverse impacts and build resilience to those social, economic and environmental shocks. It should be acknowledged that these response strategies are taken in response to the complex interplay of both climatic and non-climatic conditions including political, economic and socio-environmental changes (Mertz et al., 2010).

Theoretical literature on vulnerability shows that the understanding of local perceptions is very important in an attempt to address vulnerability and build resilience among rural agricultural households. The literature suggests that responses to vulnerabilities depend among other things on perceptions of the existing vulnerabilities and their potential harm. However, looking at the existing literature in Tanzania little is known about how local perceptions drive the choice of responses to agricultural production vulnerabilities.

Therefore, this study aimed at assessing intervention strategies for addressing agricultural production shocks due to two reasons. First, there is not enough empirical data related to intervention strategies for addressing agricultural production shocks among smallholder farmers in Tanzania. The theoretical literature provides a normative analysis and therefore there is a need for further empirical research. Secondly, there is no study that I am aware of that has, in specific terms, assessed the intervention strategies for addressing agricultural production shocks in the study area namely Rufiji, Sumbawanga and Mbarali districts. 


\section{Methodology}

\subsection{Research Approaches}

This study employed mixed research methodology. Concurrent mixed design was used where by qualitative and quantitative data were collected at the same time during the study and the information was integrated in the interpretation of the overall results. Qualitative and quantitative data were collected concurrently to best understand smallholder farmers' perceptions of possible intervention strategies for addressing agricultural production shocks and build resilience among smallholder farmers. The mixed methodology was chosen in order to overcome the limitation of using one method and to allow a comprehensive understanding of the research problem.

\subsection{Data Collection Procedures}

The study employed various techniques of data collection. Both primary and secondary data, qualitative and quantitative data were collected to meet objectives of this study. Primary data were collected using questionnaires, in-depth interviews, Focus Group Discussions (FGDs) and non-participant observation. Secondary data were collected through documentary review.

\subsubsection{Questionnaires}

Questionnaire survey was used to collect primary data in this study. There were two sets of questionnaires. The first set was administered to the heads of households who were sampled for this study. This set of questionnaire aimed at capturing information related to household characteristics, perceptions of vulnerability and response strategies adopted by the households. The questionnaires consisted of both open-ended and close-ended questions. The close-ended questions were used to collect specific information including household characteristics like ages, response strategies, incomes, and household size. Open-ended questions were used to capture in-depth information related to the local perceptions and the dynamics of household responses to agricultural production vulnerabilities.

The second set of questionnaires was administered to local government officials such as Village Councillors, Ward Councillors, Village Executive Officers (VEOs) and Agriculture Extension Officers. This set of questionnaires aimed at collecting information about administrative divisions of the study area, socio-economic characteristics and farmer-local government interactions. It also aimed at affirming the general information related to the types of crops grown in the area, the challenges facing the farmers and the alternative strategies adopted by the farmers in response to agricultural shocks.

\subsubsection{In-depth Interviews}

There were two categories of in-depth interviews. The first set was administered to farmers and the second set was administered to local government officials. On the part of the farmers, face-to-face interviews were administered to thirty (30) key informants from households that were chosen for this study. The interview enabled the key informants to provide livelihood biographies and detailed explanations of their perceptions of the existing vulnerabilities and how households respond. In most cases, the interviews focused on qualitative data.The aim of using qualitative interview to study local perceptions and responses to agricultural vulnerabilities was to generate a range of ideas and perceptions about vulnerability and the households' experiences with it. Also, interview data helped in the mapping of respondents' perceptions overtime and space with the aim of building up a detailed picture of how local perceptions drive the choice of household responses to shocks.

In attempting to answer research questions, the interview asked questions on the major threats to agricultural production, other sources of income and technologies used in agriculture. It also sought information on extension-seeking behaviour of the households. These lines of enquiry aimed at understanding the agricultural shocks and how farmers' perceived them. Understanding of other sources of income became a starting point for a researcher to explore alternative strategies or responses adopted by farmers in response to agricultural production shocks.

The second set of interview was administered to local government officials who were familiar with agricultural practices, vulnerabilities, coping and adaptation strategies. The most important resource persons were Ward Executive Officers and Agricultural Extension Officers. Data related to local history, and the socio-economic vulnerabilities in the study area could best be obtained from the farmers themselves, but of equal value were discussions with local officials. 


\subsubsection{Focus Group Discussions (FGDs)}

The Focus Group Discussions (FGDs) were conducted to collect primary data.A total of nine (three in each district) FGDs were conducted. For purposes of FGDs, a sample was divided into three groups: Male heads of households, female heads of households, and old men. Each FGD involved a group of eight (8) heads of households that were chosen randomly from each group. The random selection was done as follows: The names of heads of households were written in separate pieces of paper. The names were folded and put in a basket and mixed up. The papers were picked randomly until when the desired group size had been achieved.

The participants in the FGDs were asked to discuss on issues related to the socio-economic conditions of the villages, major crops grown in the study area, sources of production vulnerabilities and household responses. Also the FGDs focused on households' access to agricultural inputs, suitability of the soil, temperature, rainfall trends, and the trend of agricultural productivity. These discussions complemented the open-end questions of the household questionnaire regarding local perceptions and households' responses including coping and mitigation strategies. It was possible to go deeper and more precisely into these topics by asking probe questions.

\subsubsection{Non-participant Observation}

Whilst data derived from FGDs allow evidence to emerge about farmers' responses to production shocks, observation is the only way to examine the real practice at farm-level. This method involved direct observation of socio-economic activities in the study area. The use of observation in this study attempted to bridge the gap between farmers' knowledge of agricultural practices and actual scenario in the natural setting. The distinctive feature of observation method is that it allows the researcher to directly observe what is taking place in the natural setting rather than relying on second hand-information (Cohen et al., 2007).

The literature on research methods has categorized observation technique into three types namely complete (disguised) observation, participant observation and non-participant observation (Denscombe, 2007; Kothari, 2005). This study adopted non-participant observation because the first two methods were unsuitable for this study. Complete observation was unsuitable because it would not be possible for a researcher to be a complete observer of farming activities in the field without farmers' awareness. Participant observation was also discouraged despite its usefulness in minimizing the Hawthorne effect. The participant observation requires the researcher to conceal his identity at least to some of those in the setting (Denscombe, 2007). This would raise ethical issues particularly when it comes to farmers' privacy and confidentiality. In addition, "hidden identities" are highly discouraged in most rural areas in Tanzania. Farmers would prefer to have adequate information about the guests and the reasons for their presence. To avoid misunderstands non-participant observation was chosen and the researcher disclosed his identity to sample farmers.

Literature offers three forms of non-participant observation namely structured, semi-structured and unstructured observation (Cresswel, 2012). This study adopted a semi-structured observation. This decision was reached due to the limitations of structured and unstructured observations. A structured observation may lead to loss of some important data because the use of a checklist guided by pre-determined items could lead to omission of some insights emerging in the field (Mulhall, 2003). Similarly, unstructured observation might be difficult to handle because its data covers a very broad spectrum.

The use of non-participant observation enabled the researcher to observe in natural setting what has been explained by the farmers and collect in depth information about various coping strategies used by the farming households. During observation some photographs were taken in order to triangulate data collected through other methods of data collection.

\subsubsection{Transect Walks}

In order to gain an in-depth understanding of farmers' experiences and agro-economic activities, transect walks were conducted across the study villages. A transect walk is a participatory approach whereby the researcher or research team walks through a village or community (Pretty, 1995; Sallu et al., 2009). Each transect walk consisted of the researcher, one research assistant, Village Executive Officer and a group farmers ranging from two to four farmers. A total of twelve transect walks (two in each study village) were conducted during the field survey. In all six study villages, transect walks were conducted after FGDs whereby few members accompanied the researcher in walking across the village.

The major purpose of conducting transect walks was to collect more information to supplement data collected during the interviews and FGDs. In addition, transects walks were used to triangulate data collected from other methods such as documentary review, interviews and FGDs. This method helped to add some more details on livelihood activities, settlement patterns, soils and land use. Furthermore, the use of transect walks allowed the 
researcher to observe the patterns of non-farm income diversification activities implemented by the farmers in response to agricultural production shocks.

During these walks, the farmers displayed great interest and were most often in agreement with each other's opinions. They also seemed to have many ideas regarding coping strategies and local policy interventions, which have been highlighted in this study, but further probing revealed that some of these ideas were not being practised because of lack of commitment among the farmers. For instance, the farmers in one village identified a type of soil which they said could be used to make bricks to supplement household incomes especially during dry season. They emphasised that the sale of bricks could be one among the coping strategies during bad harvest, yet no one explored this lucrative opportunity.

\subsubsection{Secondary Data Sources}

Secondary data were collected through documentary review. Documentary reviews were very useful in collecting data related to ecological zones, socio-economic characteristics and demographic characteristics of the study area. A detailed explanation of secondary data sources is provided below.

\subsection{Target Population}

The target population for this study were the smallholder farmers in Rufiji, Mbarali and Sumbawanga districts in Tanzania.Sample of 510 respondents was chosen from six villages in those three districts of which all were the heads of households. Three sampling techniques were used: purposive sampling, simple random sampling and snowball sampling. While purposive sampling was used to sample the villages, simple random sampling and snowball sampling were used to sample the respondents for the study.

\subsection{Sample Size and Sampling Procedures}

The study used a sample of 510 respondents selected from the study area. Three stages were employed in the process of selecting a sample for this study. The first stage was the sampling of wards and villages in the selected districts. Purposive sampling was used to select wards and villages with a significant population of farming households. This was done after the discussion with the District Executive Directors (DED) in the study areas. This discussion focused on understanding the urban wards where there were limited agricultural activities taking place and rural wards with agricultural activities taking place. By the end of this stage, six villages (two from each district) were selected for the study. The villages were Chumbi and Mohoro (from Rufiji district), Igumbilo and Uturo (from Mabrali district), and Kaengesa and Mpui (from Sumbawanga district).

The second stage involved the choice of households for this study. The heads of households were selected from the chosen villages in the wards. This study adopted a simple random sampling and snowball sampling to sample heads of households for questionnaire survey. Village government officers were consulted to provide lists of heads of farming households. Where the lists were available simple random sampling was used while snowball sampling was used when the list of farming households was not available. In using a snowball sampling, the researcher initially met with farming households identified by the Village Executive Officers (VEO), and asked them to identify more farming households. The defining characteristic of snowball sampling is that researchers identify few individuals who have the characteristics in which they are interested. These people are then used as informants to identify others who qualify for inclusion in the sample (Cohen, 2008).

The third stage involved the choice of heads of households for the questionnaire survey. In each sampled household a head of household was chosen for survey. However, to ensure representation of female headed households (FHHs) a count was normally made and where they were not represented some adjustments were made to ensure a reasonable number of FHHs featured in the sample.

\subsection{Research Design}

This study combined exploratory design and descriptive design. In this research, exploratory design has been selected because of its usefulness in discovering ideas and insights related to vulnerability while descriptive design was chosen due to its strength in describing a phenomenon in the study. There were various aspects under investigation that required the use of description. For instance, descriptive design was used in describing response strategies as well as the nature of agricultural production vulnerabilities, historical dynamics of vulnerability and changing response strategies.

A survey strategy was used to achieve objectives of the study. This strategy is well suited to descriptive studies, and can also be used to explore aspects of a situation, or to seek explanation. For purposes of this study, a cross-sectional survey which involves collecting data at one point in time was used in examining local perceptions and responses to agricultural production vulnerabilities. Cross-sectional survey design has the 
advantage that it helps to examine current attitudes, beliefs, opinions, or practices (Creswell, 2012).

\section{Results and Discussion}

The findings of this study indicated that farmers identified various issues that need local policy intervention. The key local policy and intervention strategies identified include provision of credit facilities and subsidies on agricultural inputs $(90.3 \%)$, promoting information access and training to smallholder farmers $(89.3 \%)$ and supporting income diversification $(88.9 \%)$. The analysis further showed that 87.1 per cent of the respondents identified introduction of participatory village land use plans to address the risk of farmer-herder conflicts and land degradation as appropriate policy and strategic interventions. The intervention was mostly selected one by farmers in villages like Igumbilo, Uturo, and Chumbi where there were reports of farmer-herder conflicts. Other policy and intervention strategies according to farmers' preference include: enhancing affordable small scale irrigation technologies $(85 \%)$, reinforcing and strengthening informal social networks $(61 \%)$, and introduction of crop insurance to farmers $(58 \%)$.

Table 1. Proposed policy and intervention strategies

\begin{tabular}{lcc}
\hline Policy/ Intervention & Frequency & Percent (\%) \\
\hline Provision of credit facilities and subsidies & 456 & 89.4 \\
Promoting access to information and training & 451 & 88.4 \\
Supportingincome diversification Activities & 449 & 88 \\
Introduction of participatory village land use plans & 440 & 86.3 \\
Enhancing small-scale irrigation technologies & 429 & 84.1 \\
Reinforcing and strengthening informal social networks & 308 & 60.4 \\
Introduction of crop insurance & 293 & 57.5 \\
\hline Others & 99 & 19.4 \\
\hline
\end{tabular}

Source: Field survey, 2017

Table 1 above shows the major policy and intervention strategies identified by the farmers. These strategies are explained in detail in the remaining subsections of this paper.

\subsection{Provision of Credit Facilities and Subsidies on Agricultural Inputs}

It is interesting to find that majority of the farmers (89.4\%) identified provision of credit facilities and subsidies on agricultural inputs as important policy intervention that can support them to address vulnerability and enhance resilience to production shocks. At village level slightly similar results were obtained. The percentages of farmers who mentioned provision of credit facilities and subsidies on agricultural inputs were as follows: 95.2 per cent in Chumbi, 94.1 per cent in Mohoro, 83.5 per cent in Igumbilo and 85.8 per cent in Uturo while in Kaengesa and Mpui villages the percentage of farmers was 89.4 and 88.2 per cent respectively. This finding is similar to Shetty (2004) who observed that for enhancing agricultural productivity and building long-term resilience among smallholder farmers, better institutional credit delivery mechanisms were to be conceptualized, planned and executed urgently. Salami and Arawomo (2013) added to the above arguments and opined that without access to credit it is not possible for small and marginal farmers to carry out their activities.

\subsection{Reinforcing and Strengthening Informal Social Networks}

In this research informal social networks are defined as relationships between a limited number of individuals or households who know each other and are bound together by kinship, friendship, or convenience. Informal networks are 'institutions' in the sociological sense of having patterned and recurring interaction (Putnam, 2000). Unlike formal institutions, in most cases informal social networks do not have formal structure as there is no principal but rather a platform for agents to exchange information, goods and services. In addition, they lack legal recognition, employed staff, written rules and own funds.

Studies have demonstrated that social networks play an important role in rural development and enhancing agricultural production (Cramb, 2007). Not surprisingly, farmers in the study area reiterated about the need for enhancing and strengthening social networks as one key policy intervention for addressing agricultural production vulnerabilities. During FGDs farmers explained the benefits of their social networks to include: (i) 
obtaining knowledge on production techniques, learned during conversation and visits to other farms, (ii) obtaining informal credit particularly from friends and relatives and (iii) accessing agricultural inputs like power tillers on rental basis. To that effect households should be encouraged to engage in informal social networks so as to share information on production techniques amidst variable production conditions. This could be done through promoting social relations among households and the formation of voluntary associations. These associations will not only promote households' access to information, but will also offer them opportunities to access loans from banks.

\subsection{Support Income Diversification Activities}

The findings of this study indicate that there should be policies to strengthen the resilience of farming households through facilitating the engagement of farmers in alternative income generating activities. Elsewhere in Africa studies have found that households that undertake a wider range of livelihood activities are less vulnerable to both climatic and non-climatic shocks, while households that depend solely on crop farming are more vulnerable to shocks (Barrett et al, 2001; Guvele, 2001; Niehof, 2004). In addition, farmers who have a greater diversity of income sources have a comparative advantage over those with lower diversity. Thus under the context of environment uncertainty, most rural households especially farmers avoid an extended period of dependence on only one source of income (Ellis, 2000).

The findings of the study indicated that about $88 \%$ of the farmers highlighted the need for supporting income diversification strategies to enable farming households to diversify their livelihood strategies and to cope with agricultural production shocks. It was very interesting to observe that with exception of Mohoro and Chumbi, in the remaining four villages the percentage of farmers who pointed out to the need for supporting income diversification was very high ranging between $90.6-92.9$ per cent. This is possibly due to the fact that the four villages share similar experiences in income diversification. They are the villages in which farmers are involved in small-scale commercial farming with more diversified economic activities.

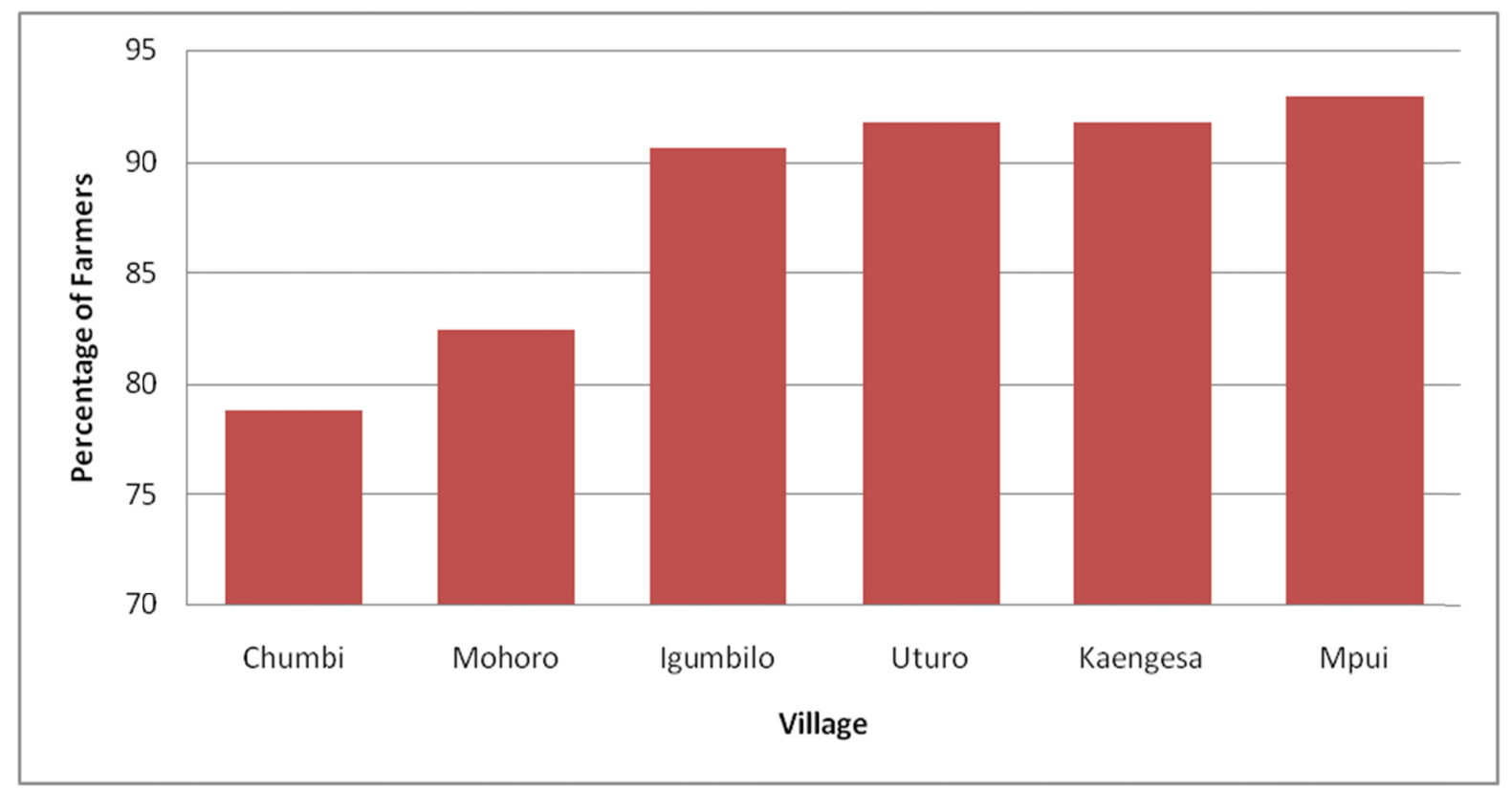

Figure 1. Supporting income diversification activities

Figure 1 above shows that majority of the farmers in the study area pointed out the need for supporting income diversification activities. From the study findings, local policy should therefore focus on improving the factors that enhance income diversification while minimizing the factors that constrain farmers' involvement in non-agricultural activities. This will help in risk mitigation and reduce dependence on a few traditional agricultural exports which face production risk.

Farming households in the study area are already involved in non-farm economic activities like petty trade, charcoal making, food vending and fishing as a response to production shocks. These findings affirm the need for local policy interventions in supporting income diversification among smallholder farmers in the study area. 
The policy should target the farmers in terms of appropriate programmes for capacity building to enable farming households to venture into non-farm economic activities.

Income diversification policy should therefore concentrate on aspects related to increasing household skills and assets in order to take advantage of complementarities between different portfolios of farm and non-farm activities while simultaneously insuring against income risk (Malunda, 2011). Also, diversification opportunities for smallholder farmers need to be identified followed by the creation of access to credit and training in order to enable farmers to pursue the diversification opportunities. Furthermore, the development of entrepreneurship and business skills is pivotal for the success of any intervention for alternative income generation. Smallholder farmers often lack even the most basic skills to develop a business and manage a small or medium enterprise.

\subsection{Introduction of Crop Insurance to Farmers}

Agriculture provides a livelihood to about $80 \%$ of Tanzanians (World Bank, 2011), with the sector dominated by smallholder farmers cultivating. However, despite the importance of agriculture, agricultural insurance for smallholder farmers is virtually absent in the market in rural Tanzania, with the exception of few pilot programs. This situation adversely affects farmers because when households lack access to insurance; production shocks not only have a direct effect on welfare when they occur, but also impact households' decisions about their livelihood activities. The belief that something bad may happen in future affects household behavior, causing households who are unprotected to avoid investing on risky activities. Dercon (1996) observed that in Tanzania farmers who lack access to crop insurance are more likely to grow safer crops and as a result earn a lower return. In this context, introduction of crop insurance to support farmers in overcoming production risks should be an area of policy interest.

Worldwide, the need for crop insurance in managing crop production risks has been widely appreciated and documented (Hazell, 1991; Robert \& Dick, 1991; Mark, 2005 and Robert, 2005). The advantages of crop insurance are many but the basic one is that of guaranteeing protection against crop failures due to occurrence of production shocks. This advantage has far reaching implications on enabling farmers to access credit, venture into new farming technologies and thus make way for greater investments in agriculture (Akyoo et al, 2013).

During the survey farmers explained the need for crop insurance to help them address the negative impacts of production shocks. Unsurprisingly, this intervention was mostly pointed out by farmers with at least primary education. One reason explaining this observation is that farmers with formal schooling have added advantage of understanding the activities and scope of insurance schemes. During FGDs it was observed that some farmers were completely unaware of what insurance is let alone the importance of crop insurance.

In addition, field survey indicated that with exception of Mohoro village the percentage of farmers who mentioned crop insurance was above 50 per cent in the rest of the villages indicating how important crop insurance is to smallholder farmers. This finding is consistent to several other studies in Tanzania (Saris et al., 2006; Ng'elenge', 2008 and Akyoo, 2013) that affirmed the importance of crop insurance schemes. Nevertheless, these results are yet to translate into local policy interventions as smallholder farmers do not have access to crop insurance services. Thus this study recommends the need to introduce crop insurance policy. The process should start by researching into the right insurance products for smallholder farmers followed by investing in training to develop an understanding of products among farming households. For successful implementation of this process there should be public-private partnership that takes on board the views of farmers.

\subsection{Introduction of Participatory Village Land Use Plans}

The importance of participatory village land use plans (PVLUP) has been recognized in the guidelines for participatory village land use management of 1998. Since then three editions of villagers participatory land use planning guide books have been released. The Village Land Act No 5 of 1999 affirmed the role of PVLUP such that it is now obligatory for every village to prepare a land use plan. In addition, the land use planning Act No 6 of 2007 elaborates that obligation by establishing the village council to facilitate the process.

As observed in chapter five of this study, land degradation and farmer-herder conflicts are among the key challenges facing smallholder farmers in the study area. In order to address these challenges there is a need for PVLUP. Land use planning is the tool for reconciling competing interests in land between individuals as well as groups, and between different villages. Thus a participatory land use plan which anticipates and guides future land use while respecting existing uses represents an effective tool for preventing and solving land conflicts. Whereas top-down planning approaches fail if not supported by local communities, local efforts may collapse without higher level support (Bakena, 1984). A bottom-up planning assures that village land-use plans are in line with regional or national plans and policies, and that planners and decision makers at the District to National 
level are sufficiently informed about the priorities identified by villagers.

During FGDs participants emphasized the need for PVLUP as a way of addressing farmer-herder conflicts and control land degradation. Conflicts between farmers and herders in Chumbi, Mohoro, Igumbilo and Mpui villages exemplify the need for the local authorities and other stakeholders to prepare village land use plans, which will clearly draw lines to separate farmers and pastoralists and to design mechanisms for enforcing the plan. This can be done through participatory preparation of land use maps as well as by local agreements, consisting of or being accompanied by land use regulations. At the core of Village land use planning is the joint balancing of competing land uses by all stakeholders and the joint identification of sustainable use of village land which is currently threatened by land degradation.

The findings of the study indicated that with exception of Kaengesa and Mpui villages, at least $90 \%$ of the respondents pointed out the need for participatory village land use plans in the remaining four villages (Figure 2). One reason explaining this observation is that the four villages namely Chumbi, Mohoro, Kaengesa and Mpui experices land use conflicts between farmers and pastoralists as well as agro-pastoralist.

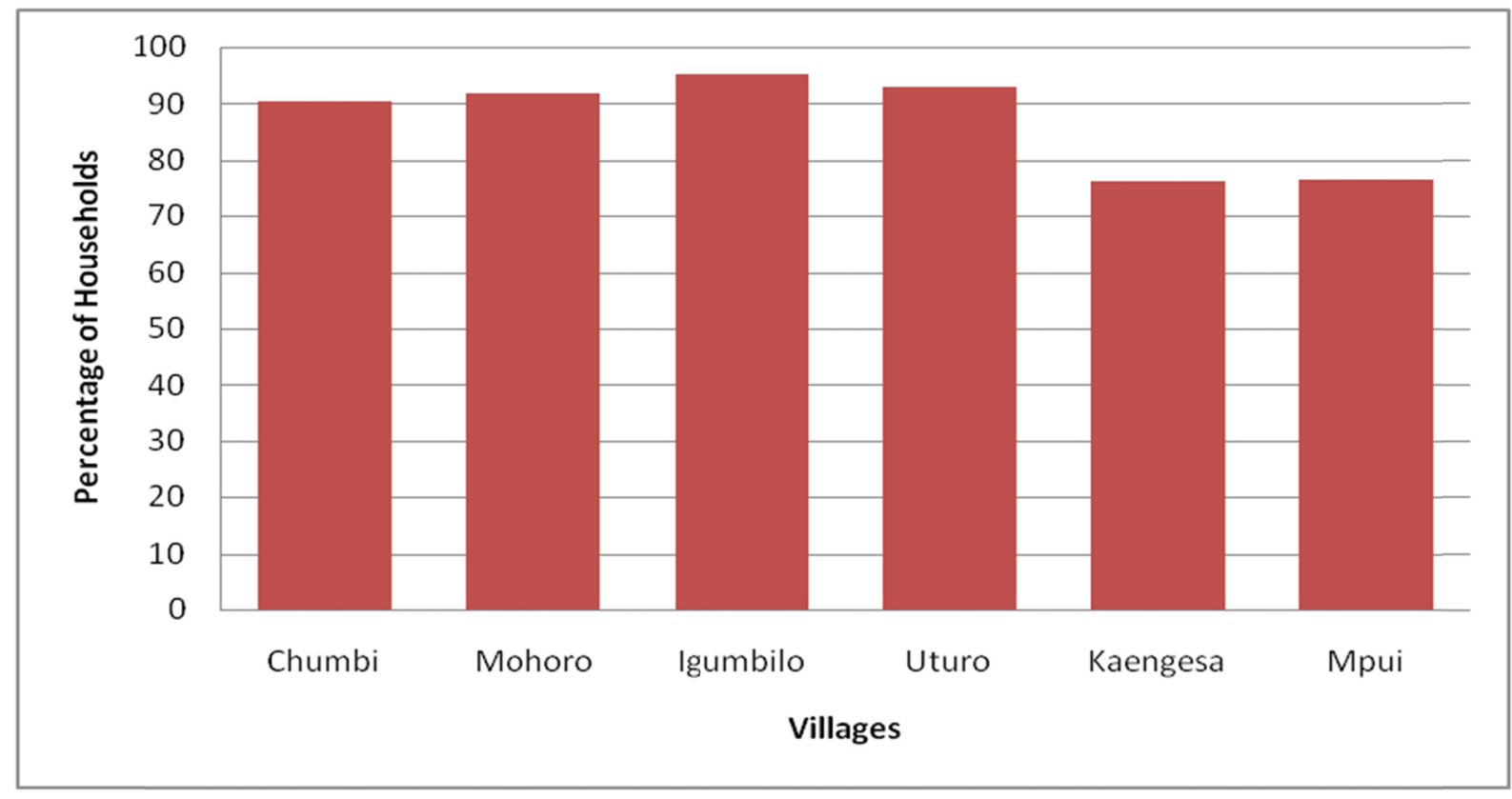

Figure 2. Introduction of participatory village land use plans

\subsection{Promote Information access and Training to Smallholder Farmers}

Smallholder farmers in the study area require up to date information and training in order to effectively and efficiently perform their farming practices. The information and training that farmers demand may cover areas like new farming methods, sustainable land management, availability of weather forecast and supply of inputs and outputs, among others. Oxfarm (2009) observed that small-scale farmers are often marginalized by their lack of training and access to information about both growing conditions and markets.

The findings from household interviews indicated that $88.4 \%$ of farming households identified the promotion of information access and training as one of the policy interventions for addressing agricultural production vulnerabilities. It was interesting to observe that the percentages of the farmers who selected this item were close to each other across the study villages. The highest percentage was observed in Chumbi and Mpui villages (about 89.4\%) while the lowest percentage was observed in Igumbilo (about 87.1\%). In Mohoro, Uturo and Kaengesa villages the percentage was $88.2 \%$ while in Mpui village it was $89.4 \%$. These high percentages reflect how important access to information and training is to farming households.

The findings above were affirmed during FGDs where the participants were of the opinion that the government should improve access to information on agricultural production including information on the distribution of rainfall during the farming season, sustainable land use methods and improved production technologies. This calls for appropriate and timely dissemination of information to farmers using various channels such as local radio stations broadcasting in local languages spoken in the sample villages. The government and other 
stakeholders need to research new approaches to information dissemination that grow out from a clear understanding of farmers' information needs and information channels that are effective for the farmers (FARA, 2006). Furthermore, efforts should be made by government authorities to train farmers on better farming practices. In this regard, strengthening the capacity of extension officers through increased staff numbers and training is very crucial.

The findings and recommendations above are concurrent to World Bank (2007) who has pointed to the need for information to be adequate and responsive to farmers' needs and suggested that shortcomings in information to farmers might be a major hindrance for agricultural productivity and market access by farmers. In the same line of argument, Solano et al. (2003) assert that unless more efforts are placed on the importance and the dynamics of information flows to farmers, suitable mechanisms for enabling market access and thus increase in income are unlikely to be found.

\subsection{Enhancing Access to Small-Scale Irrigation Technologies}

Finally, the importance of small-scale irrigation technologies in addressing agricultural production vulnerabilities should be recognized. In this study small-scale irrigation refers to irrigation activities undertaken by smallholder farmers who own and manage an individual plot or are part of a community managed irrigation scheme that covers up to 200 hectares. The term "small-scale irrigation" therefore covers a wide range of irrigation activities ranging from bucket and drum kits with low-cost drip lines of individual farmers to joint irrigation schemes in which individual small farmers participate as users.

The findings of the study indicated that about $84.1 \%$ of the respondents explained the need for small-scale irrigation facilities as a better way of responding to production shocks arising from rainfall variability. Data from villages indicated that with exception of Uturo village more than $85 \%$ of the farmers in the remaining villages pointed to the need for small-scale irrigation facilities. This observation is attributable to the presence of Uturo irrigation scheme which serves the farmers in Uturo village. Thus in comparison farmers in Uturo village have lesser demand for new irrigation facilities compared to farmers in villages where irrigation facilities do not exist.

It is important to emphasise that farmers, especially those in Chumbi, Mohoro, Kaengesa and Mpui rely on rain-fed farming and have one farming season. In addition, smallholder farmers in all sample villages experience other challenges like poor access to agricultural inputs and land degradation. Thus, any interruption in the rains during the farming season could have devastating impacts not only on food security but also the livelihood security of the farming households. Although there are a few irrigation facilities available to farmers, especially those in Uturo village, the majority of farming households do not have access to irrigation. This observation calls for the need to introduce small-scale irrigation to assist the farmers. Elsewhere in Africa studies have acknowledged the role of small-scale irrigation for farming households. For instance, a study by Haji and Aman (2013) in Ethiopia revealed that access to small-scale irrigation scheme has significantly reduced the incidence, the depth and the severity of households' poverty.

\section{Conclusion}

This paper aimed at identifying and explaining local policy interventions for addressing agricultural production shocks. Seven key areas of intervention have been identified by the farmers. The key interventions include provision of credit facilities and subsidies, promoting access to information and training, supporting income diversification activities and introduction of participatory village land use plans. Other key intervention strategies suggested by the farmers were enhancing small-scale irrigation technologies, reinforcing and strengthening informal social networks and introduction of crop insurance scheme. From these findings, it is recommended that policy makers and other stakeholders in agriculture sector should effectively implement these strategies in order to address vulnerability and build resilience among agricultural households.

\section{Acknowledgements}

This article is based on the research conducted in fulfilment of the requirements for the Doctoral degree at the University of Dar es Salaam, Tanzania. The research was financially supported by the Dar es Salaam University College of Education (DUCE) and Higher Education Students' Loans Board (HESLB) of Tanzania. The authors acknowledge all institutions and individuals that supported this study.

\section{References}

Acquah-de Graft, H., \& Onumah, E. (2011). Farmers' perceptions and adaptations to climate change: An estimation of willingness to pay. Agris, 3(4), 31-39.

Akyoo, A. M., Temu, A. E.,\& Hella, J. P. (2013). Agricultural production risks, coping mechanisms and potential 
for crop insurance in Tanzania. Time Journals of Agriculture and Veterinary Sciences, 1(1), 11-22.

Bakema, R. J. (1984). Land Tenure and Sustainable Land Use (Bulletin 332). Amsterdam: Royal Tropical Institute.

Below, T., Artner, A., Siebert, R.,\& Sieber, S. (2010). Micro-level Practices to Adapt to Climate Change for African Small-scale Farmers A Review of Selected Literature (IFPRI Discussion Paper No. 00953). International Food Policy Research Institute.

Cohen, L., Manion, L., \& Morrison, K. (2007). Research Methods in Education (6th ed). London: Routledge. https://doi.org/10.4324/9780203029053

Cramb, R. A. (2007). Participation in community landscare groups in the Philippines: A social capital perspective. Australasian Journal of Environmental Management, $14(2), \quad 93-102$. https://doi.org/10.1080/14486563.2007.10648706

Creswell, J. W. (2012). Educational research: Planning, conducting, and evaluating quantitative and qualitative research (4th ed). New York: Pearson.

Denscombe, M. (2007), The good research guide: for small-scale social research projects. Maidenhead, New York: Open University Press.

Dercon, S. (1996). Risk, crop choice and savings: Evidence from Tanzania. Economic Development and Cultural Change, 44(3), 385-514. https://doi.org/10.1086/452229

Ellis, F. (2000). The Determinants of Rural Livelihood Diversification in Developing countries. Journal of Agricultural Economics, 51(2), 289-302. https://doi.org/10.1111/j.1477-9552.2000.tb01229.x

Food and Agriculture Organization. (2012).Coping with the food and agriculture challenge: smallholders' agenda.Preparations and outcomes of the 2012 United Nations Conference on Sustainable Development. Rome: FAO.

Framework for African Agricultural Productivity. (2006): Framework for African Agricultural Productivity. Retrieved from http://faraafrica.org/wp-content/uploads/2015/04/FAAP_English.pdf

Guvele, C.A. (2001). Gains from crop diversification in the Sudan Gezira scheme. Agric. Syst., 70, $319-333$. https://doi.org/10.1016/S0308-521X(01)00030-0

Hassan, R., \& Nhemachena, C. (2008). Determinants of African farmers' strategies for adapting to climate change: Multinomial choice analysis. African Journal of Agricultural and Resource Economics, 2(1), 83-104.

Jain, R.C.A., \& Parshad, M. (2007). Report of the working group on risk management in agriculture for the eleventh five year plan: 2007-2012.New Delhi: Planning Commission.

Mbiha, E. R., Ephraim M. M.,\& Senkondo, E. M. M. (2001). A Socio-economic profile of the Rufiji floodplain and delta (Technical report No. 6, volume 1). Dar es Salaam: Rufiji Environment Management Project.

Mulhall, A. (2003). In the field: notes on observation in qualitative research. Journal of Advanced Nursing, 41(3), 306-313. https://doi.org/10.1046/j.1365-2648.2003.02514.x

National Burea of Statistics. (2014). Basic Demographic and Socio-Economic Profile Report Tanzania Mainland. Dar es Salaam: National Bureau of Statistics.

Ndaki, P. M. (2016). Climate Change Adaptation for Smallholder Farmers in Rural Communities: the Case of Mkomazi Sub-Catchment, Tanzania. Retrieved from https://d-nb.info/1060480875/34

Niehof, A. (2004). The Significance of diversification for rural livelihood systems. Food Policy, 29, $321-338$. https://doi.org/10.1016/j.foodpol.2004.07.009

Salami, A., \& Arawomo, D.F. (2013). Empirical Analysis of Agricultural Credit in Africa: Any Role for Institutional Factors? (Working Paper Series No. 192). Tunis: African Development Bank.

Sarris, A., \& Karfakis, P. (2010), Vulnerability to Covariate and Idiosyncratic Shocks and Safety Net Targeting of Rural Households with an Application to Rural Tanzania. Paper presented at the European Report on Development workshop on "Experiences and lessons from social protection programmes across the developing world: what role for the EU?" Paris, June 17-18, 2010.

Schlenker, W., \& Lobell, D.B. (2010). Robust negative impacts of climate change on African agriculture. Environmental Research Letters, 5(1). https://doi.org/10.1088/1748-9326/5/1/014010 
Schwarze, S., \& Zeller, M. (2005). Income diversification of rural households in Central Sulawesi, Indonesia. Quarterly Journal of International Agriculture, 44(1), 61-73.

Shemsanga, C., Omambia, A.N., \&Yansheng Gu, Y. (2010). The Cost of Climate Change in Tanzania: Impacts and Adaptations. Journal of American Science, 6(3), 182-196.

Shettima, A. G., \& Tar, U. A. (2008). Farmer-pastoralist conflict in West Africa: Exploring the causes and consequences. Information, Society and Justice, 1(2), 163-184.

Solano, C., Leon, H., Perez, E., \&Herrero, M. (2003). The Role of Personal Information Sources on Decision Making Process of Costa Rican Dairy Farmers. Agricultural Systems, $76(1)$. https://doi.org/10.1016/S0308-521X(02)00074-4

World Bank. (2007). Agriculture for development: World Development Report 2008. Washington DC: World Bank.

World Bank., Organization for Economic Cooperation and Development. (2015). Africa Competitiveness Report 2015. Cologny: World Economic Forum.

World Meteorological Organization. (2009). Improving weather monitoring in Africa. Retrieved from http://www.wmo.int/pages/publications/

Wye, C. (2003). Overcoming Informational constraints: Improving horticultural marketing and technical information flows to smallholders, literature review. London: Imperial College.

Zeller, M. (2000). Determinants of Credit Rationing: A Study of Informal Lenders and Formal Credit Groups in Madagascar. World Development, 22(12), 1895-1907. https://doi.org/10.1016/0305-750X(94)90181-3

Zingore, S., Delve, R. J., Nyamangara, J., \& Giller, K. E. (2008). Multiple Benefits of Manure: The key to Maintenance of Soil Fertility and Restoration of Depleted Sandy Soils on African Smallholder Farms. Agroecosystem, 80, 267-282. https://doi.org/10.1007/s10705-007-9142-2

\section{Copyrights}

Copyright for this articleis retained by the author(s), with first publication rights granted to the journal.

This is an open-access article distributed under the terms and conditions of the CreativeCommons Attribution license (http://creativecommons.org/licenses/by/4.0/). 